\title{
Hasta Ailesinin, Nöroloji Yoğun Bakım Hemşireleriyle İletişiminin Araştırılması*
}

\author{
Dilek BAYKAL ${ }^{* *}$, Aysel ÇAVUŞOĞLU***, Sevda ÖZTÜRK ERDEN****
}

$\ddot{O} \mathbf{z}$

Amaç: Nörolojik hastalıklar akut ve progresif seyir göstermesiyle kronik dönemde en fazla yoğun bakıma ihtiyaç duyulan hastalıklardandır. Yoğun bakımda çalışan hemşireler hastayla olduğu kadar hasta ailesiyle de iletişim kurarlar. Özellikle yoğun bakımlarda hastada gelişen ani değişiklikler hasta yakınına yansıyabilmekte ve hemşirelerle iletişimlerinde sorunlar yaşanabilmektedir. Bu çalışmada nöroloji yoğun bakım ünitesinde çalışan hemşirelerin hasta ailesiyle iletişimleri ve etkileyen faktörlerin incelenmesi amaçlanmıştır.

Yöntem: Bu çalışmaya en az altı aydır yoğun bakım ünitesinde çalışan ve çalışmanın amacı açılandıktan sonra çalışmaya katılmayı kabul eden 10 nöroloji yoğun bakım ünitesi hemşiresi dâhil edildi. Hemşirelerle önceden telefonla görüşülerek randevu alındı. Literatürden yararlanılarak oluşturulan yarı yapılandırılmış görüşme formu aracılığıyla görüşmeler gerçekleştirildi. Görüşmelerin gerçekleştirilmesi esnasında katılımcıların onamı alınarak sesli kayıt alındı, bire-bir dökümleri gerçekleştirildi. Görüşmelerin analizinde tematik analiz kullanıldı.

Bulgular: Katılımcıların yaşları ortalama $37,3 \pm 4,5$ ve çalışma süreleri 13,6 $\pm 8,92$ yıldır. Sekiz hemşire mesleğini kendi isteğiyle seçtiğini belirtirken, bir hemşire de yoğun bakım ünitesinde

Özgün Araştırma Makalesi (Original Research Article)

Geliş / Received: 29.01.2021 \& Kabul / Accepted: 31.03.2021

DOI: https://doi.org/10.38079/igusabder.870481

* 7. Nörolojik Yoğun Bakım Sempozyumu'nda poster bildiri olarak sunulmuştur (19-22 Ekim 2017, Konya, Türkiye).

** Dr. Öğr. Üyesi, İstanbul Atlas Üniversitesi, Sağlık Bilimleri Fakültesi, Hemşirelik Bölümü, İstanbul, Türkiye, E-posta: dilek.baykal@atlas.edu.tr ORCID https://orcid.org/oooo-00015965-9318

**** Uzm. Hemşire, İstanbul Üniversitesi, İstanbul Tıp Fakültesi, Nöroloji Anabilim Dalı, İstanbul, Türkiye, E-posta: ayselcav@gmail.com ORCID https://orcid.org/0000-0003-34711487

${ }^{* * * *}$ Hemşire, İstanbul Üniversitesi, İstanbul Tıp Fakültesi, Nöroloji Anabilim Dalı, İstanbul, Türkiye, E-posta: sevdaerden@yahoo.com ORCID https://orcid.org/o000-0003-4256-3736 
çalışmayı kendisinin tercih ettiğini belirtti. Katılımcıların hasta yakınlarıyla iletişim problemi yaşadıklarında günlük yaşamlarının ve özel hayatlarının olumsuz etkilendiği anlaşıldı. Ayrıca katılımcılar hasta yakınlarının kendilerine davranışlarını "saygısızca" ve "empati yoksunu" olarak tanımladılar. Son olarak yoğun bakım ve hastane koşullarının da hasta yakınlarıyla iletişim problemi yaşamalarına katkıda bulunduğu anlaşılmaktadır.

Sonuç: Genel olarak hemşirelerin hasta yakınlarının iletişim kurma şeklinden hoşnut olmadığı, hasta yakınlarının olumsuz davranışlarının iş motivasyonlarını azalttığı ve hasta yakınlarından saygı bekledikleri anlaşıldı. Hemşirelerin gözüyle hasta yakınlarının iletişim kurma biçimlerinin anlaşılması toplum sağlığına önemli katkı sağlayan hemşirelerin yaşadıklarına bakış sağlayacaktır.

Anahtar Kelimeler: Nöroloji yoğun bakım, hemşire, iletişim, hasta ailesi.

\title{
Examination of Patient Family' Communication with Neurology Intensive Care Nurses
}

\begin{abstract}
Aim: Neurological diseases are among the diseases that require the most intensive care in the chronic period, with an acute and chronic period. Nurses working in the intensive care unit communicate with the patient as well as their family. Sudden changes in the patient, especially in intensive care units, can be reflected in the relatives of the patient and problems may occur in communication with nurses. This study aimed to examine the communication of nurses working in the neurology intensive care unit with the patient family and the influencing factors.

Methods: Ten neurology intensive care unit nurses, who had been working in the intensive care unit for at least 6 months and agreed to participate in the study after the purpose of the study was explained, were included in this study. An appointment was made by talking to the nurses beforehand. Interviews were carried out through a semi-structured interview form created using the literature. During the interviews, the consent of the participants was obtained and audio recording was made, and verbatim transcriptions were made. Thematic analysis was used in the analysis of the interviews.
\end{abstract}

Results: Participants mean age $37,3 \pm 4,5$ and duration of work 13,6 48,92 years. Eight nurses stated that they chose their profession voluntarily, and one nurse stated that they preferred to work in the intensive care unit. It was understood that when the participants had communication problems with their relatives, their daily and private lives were negatively affected. In addition, the participants described the behaviours of the relatives of the patients towards themselves as 
"disrespectful" and "lack of empathy". Finally, it is understood that the intensive care and hospital conditions also contribute to the communication problems with the relatives of the patients.

Conclusions: In general, it was understood that nurses were not satisfied with the way patients' family communicated, negative behaviors of patients' family reduced their work motivation and they expected respect from their relatives. Understanding the communication styles of patients' family through the eyes of nurses will provide an insight into the experiences of nurses who make an important contribution to public health.

Keywords: Neurology intensive care, nurse, communication, patient family.

\section{Giriş}

Kronik hastalıklar, son yıllarda insan ömrünün uzaması ve gelişen teknolojiyle birlikte artmaktadır. Kronik hastalıklar içinde yer alan progresif seyir gösteren nörolojik hastalıklar kişiye, bakım vericisine ve topluma getirdiği yük nedeniyle diğer

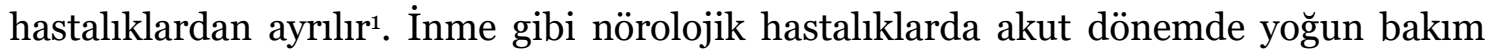
ihtiyacı olabilirken motor nöron hastalıklarda hastalığın ilerleyen safhalarında yoğun bakım ihtiyacı doğabilmektedir². Nörolojik yoğun bakımların kurulmasıyla birlikte başa çıkılması güç olduğu düşünülen pek çok hastanın yaşama döndürüldüğü görülmüştür3. Nöroloji yoğun bakım üniteleri nöromüsküler hastalıkların sonucunda görülen bağımlılık düzeyleri yüksek hastaların yattığı birimlerdir4. Bu birimlerde görev alan yoğun bakım hemşireleri kesinliği belli olmayan koşullarda çalışmaya ve tıbbi konularda hızlı karar vermeye yetkindir5 ${ }^{5}$ Kritik hastaların ve anlık değişimlerin söz konusu olduğu ünitelerde hasta yakınları ve diğer sağlık çalışanlarıyla etkili iletişim kurulması önemlidir ${ }^{6}$. Yapılan çalışmalarda yoğun bakım hastasında iletişimden çok öngörülemez durumuna ve tekrarlayan komplikasyonlarına odaklanıldığı bildirilmektedir7. Ancak ailenin ihtiyaçları farklıdır. Bu ihtiyaçların karşılanmasında hemşirelerin aileyle iletişim kurması gerekir ${ }^{8}$. Ailelerin ihtiyaçları karşılanmadığında anksiyete, stres gibi semptomların yaşandığı bildirilmektedir. Ailenin en önemli ihtiyacı hastası ve hastalığı hakkındaki bilgidir. Bu bilgi hastalığın prognozu, mekanik ventilasyon ihtiyacı, olası gelişebilecek komplikasyonlar, ağrı ve acı hissetme durumu gibi pek çok şey içerebilir`. İletişim, karşılıklı olarak birbirini anlamaya, etkilemeye çalışma, belirsizliğin azaltılması ve bağlantı kurulması olarak tanımlanır ${ }^{10}$. Yoğun bakım ünitelerinde hasta ve 
yakınlarıyla iletişim kurmak kritik durumdaki hastalara bakım verme, çalışanların yoğunluğu gibi nedenlerle sağlık çalışanları açısından daha zor olabilmektedir7. Diğer yandan yoğun bakımda hastası olan aile yakınları sağlık çalışanlarıyla yeterli iletişim kuramadıklarını belirtmektedirler ${ }^{11}$. Oysaki aile üyeleri ve sağlı çalışanları arasında etkili iletişimin kurulması her iki tarafın genel iyilik halini arttırmaktadır ${ }^{12,13}$. Sağlıklı iletişim kurulmadığında hasta bakımında eksiklikler yaşanmasına bağlı olarak hemşirelerin pişmanlık, kızgınlık, utanç ve umutsuzluk duyguları yaşadığı belirtilmektedir. Bu duygular hemşirede özgüvenin ve özsaygılarının azalmasına yol açabilmektedir ${ }^{14}$.

Yoğun bakım hemşirelerinin iletişim kurma deneyimlerinin öğrenilmesi önemlidir. Hemşireler, iletişim becerilerini kullanarak yeni bilgiler öğrenir ve öğrendiği bilgileri hastasının sağlık problemlerini çözmede kullanır. Hastasının bakım tercihlerini, karar verme sürecini başarıyla yönetir15. Özellikle hasta ve ailesi merkezli iletişim kurulması hasta güvenliğini arttırırken bakım kalitesini de arttırır ${ }^{16}$. Yoğun bakım hemşirelerinin hasta ve yakınlarıyla iletişim becerilerini sürekli olarak geliştirmeyi hedeflemesi gerektiği belirtilmektedir ${ }^{17}$.

Ancak kritik hastalara bakım veren ve anlık tıbbi kararların verildiği ünitelerde bu her zaman mümkün olamamaktadır. Bu ünitelerde çalışan sağlık profesyonelleriyle hasta yakınlarının iletişim kurma biçimlerinin belirlenmesi etkili iletişim yollarının geliştirilmesine yardımcı olabilir.

$\mathrm{Bu}$ nedenle bu çalışmada nöroloji yoğun bakım ünitesinde çalışan hemşirelerin hasta yakınlarıyla iletişimlerinin derinlemesine görüşme yöntemiyle ayrıntılı olarak incelenmesi amaçlanmıştır. Bu çalışma hemşirelerin gözüyle hasta yakınlarının iletişim kurma davranışlarının anlaşılmasına ışık tutacak ve nöroloji yoğun bakım ünitelerinde sağlık bakım kalitesinin arttırılmasına katkı sağlayacaktır.

\section{Gereç ve Yöntem}

\section{Araştırmanın Yeri, Zamanı ve Örneklem Seçimi}

Araştırma bir üniversite hastanesinin nöroloji yoğun bakım ünitesinde Ekim-Aralık 2017 tarihleri arasında gerçekleştirilmiştir. 


\section{Etik İzinler}

Araştırma için İstanbul Tıp Fakültesi Klinik Araştırmalar Etik Kurulu'ndan etik kurul izni alındı (19.09.2017/No:14). Araştırmaya katılmayı kabul eden katılımcılardan araştırmanın amacı açıklanarak yazılı onamları alındı. Ayrıca ses kayıtlarının alınması için de yazılı onamları alındı. Çalışma boyunca Helsinki Bildirgesi’ne bağlı kalındı.

\section{Çalışma Grubu}

Araştırma üniversite hastanesinin nöroloji yoğun bakım ünitesinde en az 6 aydır çalışmakta olan hemşirelerle gerçekleştirilmiştir. Ünitede çalışan 12 hemşireden 1 hemşire gebelik izninde, bir tanesi de çalışmaya katılmak istemediği için dahil edilmemiştir. Çalışma 10 hemşire ile tamamlanmıştır.

\section{Veri Toplama Araçları}

Verilerin toplanması esnasında hemşirelerin sosyo demografik özelliklerinin sorgulandığı bilgi formu (yaş, cinsiyet, ekonomik durum vb) uygulanmıştır. Daha sonra literatür doğrultusunda hazırlanmış yarı yapılandırılmış derinlemesine görüşme formu ile görüşmeler gerçekleştirilmiştir7,9-11. Görüşmeler öncesinde çalışmaya katılmayı kabul eden hemşirelerden randevu alınmıştır. Görüşmelerin sağlıklı gerçekleştirilmesi için sessiz bir ortam sağlanmıştır. Her görüşme 30-40 dk sürmüştür. Görüşmeler sonrasında görüşmeci notları tutulmuştur.

\section{Verilerin Analizi}

Verilerin analizinde tematik analiz kullanıldı. Öncelikle görüşmeler esnasında alınan sesli kayıtların birebir dökümleri gerçekleştirildi. Araştırmacılar tarafindan bağımsız olarak temalar oluşturuldu. Daha sonra ortak temalar konusunda biraraya gelerek görüş birliği sağlandı. Tüm araştırmacılar biraraya gelerek ortak temaların ve kategorilerin hemşirelerin hasta ailesiyle iletişimini yansitacak gerçek bir temsili olduğundan emin olundu.

\section{Bulgular}

Hemşirelerin sosyo-demografik özellikleri ve araştırmacılar tarafından belirlenen 5 ana tema ve 2 alt tema aşağıda sunuldu:

i) İletişimi etkileyen koşullar 
Alt tema 1. Günlük yaşam

Alt tema 2. Yoğun bakım koşulları

ii) Hasta yakınlarının davranışı

iii) Hasta yakınları empati kurabiliyor mu?

iv) Çalışmaya başladıktan sonraki duygu ve düşünceler

v) Beklentiler

\section{Hemşirelerin Sosyo-demografik Özellikleri}

Hemşirelerin yaşları ortalama $37,3 \pm 4,5$ ve çalışma süreleri 13,6 $\pm 8,92$ yıldır. Katılımcıların 8 tanesi mesleğini kendi isteğiyle seçtiğini belirtirken, 9 tanesi yoğun bakım ünitesinde (YBÜ) çalışmayı kendisinin tercih etmediğini belirtmiştir (Tablo 1).

Tablo 1. Hemşirelerin sosyo-demografik özellikleri

\begin{tabular}{|c|c|c|c|c|c|c|c|c|}
\hline No & Cinsiyet & Yaş & $\begin{array}{l}\text { Eğitim } \\
\text { durumu }\end{array}$ & $\begin{array}{l}\text { Gelir } \\
\text { düzeyi }\end{array}$ & $\begin{array}{l}\text { Medeni } \\
\text { durum }\end{array}$ & $\begin{array}{l}\text { Çocuk } \\
\text { sayısı }\end{array}$ & $\begin{array}{l}\text { Mesleği } \\
\text { kendi } \\
\text { isteğiyle } \\
\text { mi } \\
\text { seçti? }\end{array}$ & $\begin{array}{l}\text { YBÜ'nde } \\
\text { çalışmayı } \\
\text { kendisi mi } \\
\text { istedi? }\end{array}$ \\
\hline $\mathbf{1}$ & Kadın & 47 & Önlisans & Orta & Evli & 2 & Evet & Hayır \\
\hline 2 & Kadın & 40 & Lisans & Orta & Evli & Gebe & Evet & Hayır \\
\hline 3 & Kadın & 33 & Y. lisans & İyi & Evli & 2 & Hayır & Hayır \\
\hline 4 & Kadın & 30 & Lisans & Orta & Evli & Yok & Evet & Hayır \\
\hline 5 & Erkek & 32 & Lisans & Orta & Evli & 1 & Evet & Hayır \\
\hline 6 & Erkek & 32 & Lisans & Kötü & Bekâr & Yok & Evet & Hayır \\
\hline 7 & Kadın & 47 & Lisans & İyi & Evli & 2 & Evet & Hayır \\
\hline 8 & Kadın & 49 & Önlisans & İyi & Evli & 2 & Evet & Evet \\
\hline 9 & Kadın & 28 & Lisans & İyi & Evli & Gebe+1 & Evet & Hayır \\
\hline 10 & Kadın & 35 & Lisans & İyi & Evli & 3 & Hayır & Hayır \\
\hline
\end{tabular}




\section{Ana tema 1. İletişimi etkileyen koşullar}

\section{Alt tema 1. Günlük yaşam}

Hemşirelere günlük yaşamda yaşadıkları sorunların hasta yakınlarıyla iletişimlerini etkileyip etkilemediği soruldu. Katılımcıların genel olarak günlük yaşamda yaşadıkları olumsuz olayları hasta yakınlarına yansıtmadıkları ancak hasta yakınlarıyla yaşadıkları olumsuzlukların günlük yaşamlarını etkilediği anlaşıldı.

Hiç yansıtmamaya çalışıyorum. Evdeki olay evde kalıyor. Hastane kapısından girdiğim anda tamamen başka bir kişiye bürünüyorum (K,49y).

Benim açımdan etkilemiyor. Çünkü ben eve gelince işi unutuyorum işe gidince evi unutuyorum hani kendi çocuğumu bile unutuyorum. Yani sorunları aklımda tutmamayı tercih ediyorum $(\mathrm{K}, 35 \mathrm{y})$.

Oysaki hemşirelerin hasta yakınlarıyla yaşadıkları sorunları gün içinde unutamadıkları ve bu sorunların günlük yaşamlarının kötü geçmesine yol açtığı ifadelerinden anlaşılmaktadır.

Etkiliyor tabii ki. Moralimiz o anda bozulduğunda bir daha günümüz o şekilde devam ediyor (K,47y).

İnsanız, mutlaka etkiliyoruz. Evet, hemşireyiz ama psikolojiniz bozuluyor doğal olarak ama artık tolere etmeye çalışıyorsun. Önceden o gün tamamen dibe vuruyordum ama şimdi hep bunlar oluyor diyorum. Çünkü artık biraz tecrübe oluyor. Önceden ağrılar girerdi başıma $(\mathrm{K}, 40 y)$.

Evet, etkiliyor özellikle evde çok sinirli oluyorum. Bütün buranın sinirini evdekilerden çlkartıyorum (E,33y).

Evet, etkiliyor. Çok ufak tefek tartışmalar oluyor ama meslek hayatım boyunca üçü dördü geçmez ama çok şiddetli tartışmalar yaşadığımızda mutlaka etkileniyorum. Bütün gün taşikardim tansiyonum oynuyor. O derecede etkileniyorum (K,47y).

Hemşirelerin hasta yakınlarıyla yaşadıkları sorunları fiziksel, psikolojik ve sosyal olarak yaşamlarına aktardıkları anlaşılmaktadır. Problemlerinin psikolojik yükünü sosyal çevrelerine yansıtmakta, ağrı, taşikardi ve hipertansiyon olarak da fiziksel etkilerini yaşamaktadırlar. 


\section{Alt tema 2. Yoğun bakım koşulları}

Yoğun bakımlarda kritik hastaya bakım verme ve hastaların genel durumunun her an değişiyor olması çalışma koşullarını zorlaştırmaktadır. Yoğun bakım hemşireleri de bu ortamda çalışıyor olmanın hasta yakınıyla iletişimlerini olumsuz etkilediklerini belirtmişlerdir.

Etkiliyor tabii. Hasta yakınıyla iletişim kurmaya çalışırken diğer tarafta da müdahale etmemiz gereken hastalar oluyor. Onları ertelemiş oluyoruz. Hasta yakınlarının zaten psikolojisi bozuk olduğu için tepkililer, anlattıklarımızı anlayamıyorlar. Bizim de acelemiz olduğu için kısadan kesmeye çalışıyoruz (K,47y).

İster istemez etkiliyor. Yani mesela en basiti içerdesin çok yoğun bir şekilde çalışıyorsun, kapıya tak tak sürekli vuruyorlar. Anlasalar ki içerdesin açamıyorsun ama anlatamiyorsun $(\mathrm{K}, 33 \mathrm{y})$.

Kesinlikle etkiliyordur. Normalde yorgun değilken daha güler yüzlü olabiliyorsun ama yorgunken insanlara bakmaya fırsatın olmuyor. Bir koşturma içerisinde yetiştirmeye çalışıyoruz (K,30y).

Aşırı derecede etkiliyor. Çünkü çok yoğun çalışıyoruz. Giriyoruz sabahleyin bakım yapmaya öğlene kadar çıkamıyoruz. Öğlen çıktığımız zaman bakım yaptığımız malzemeleri hasta yakınlarına aldırıyoruz. Bunları istediğimiz zaman ilk zamanda maddi olarak dokunmuyor ama tekrarlayan isteklerimiz olduğu zaman sert tepkilerle karşılaşıyoruz (E,32y).

Tabii etkiliyor insanı, çünkü bir yerden sonra kendi sağlığınızdan ödün veriyorsunuz. Koşturuyorsunuz, hasta kötüleştiği zaman daha çok efor sarf ediyorsunuz ama bunlardan hasta yakınının haberi yok (E,32y).

Moral motivasyonumuz, duygumuz geri bildirim olumluysa olumlu oluyor. Bazı hasta yakınları hastaları taburcu edilirken gülmüyor, teşekkür bile etmiyorlar. Mesela ben şununla karşılaştım hastası ex oldu. Bir hafta sonra çiçek yolladılar. Hastamıza gösterdiğiniz ilgiden dolayı teşekkür ederiz. İnsanların cenazeleri var ama bize teşekkür çiçeği yolladılar. Sonuçta biz onların hastalarına 2- 3 ay boyunca bakım verdiğimizi bir ekip çalışması yaptı̆̆ımızı biliyorlar (K,28y). 
Hemşirelerin, hasta yakınlarıyla iletişimi yoğun bakımda kritik hastaya bakım verme, hastanın ani değişen durumu, iş yoğunluğunun fazlalığı gibi koşullar nedeniyle etkilendiği anlaşılmaktadır.

\section{Ana tema 2. Hasta yakınlarının davranışı}

Hemşirelere hasta yakınlarının kendilerine nasıl davrandığını ve nasıl davranmasını istediklerini sorduğumuzda temel isteklerinin saygı olduğu anlaşıldı.

Saygılı olsalar yeterli benim için. Mesleğime saygı, kişiliğime saygı (K,47y).

Tabii ki senli benli değil. Bazılarına samimi davranıyorsun. İsmini öğreniyor. İsminle hitap ediyor mesela. Düzeltiyorsun hemşire hanım diye. Bazıları çok saygılı, bazıları saygisiz (K,4Oy).

Mesela canım falan dediklerinde ben de onu lütfen bana hemşire hanım der misiniz dediğimde düzeltiyorlar (K,49y).

Ricayla, emrivaki değil de, sonuçta işimizi yapıyoruz ama rica olunca daha güzel oluyor (K,30y).

Yani kim olursa olsun durması gerektiği noktayı bilecek insan. Nasıl ki bir doktora ya da başka birine bağırmadan hocam şöyle yapar mısın diyorsa hemşireye de bağırma lüksü yok. Çünkü doktor da, profesör de, benim gibi kendisine bakım vermekle yükümlü insanlar (E,32y).

Genel yargım şu; hemşirenin değerini hiç bilmiyorlar. Mesela bir hastaya 5-6 ay kadar baktım. Her sıkıştığında aspire edip onu ölümlerden döndürdüm. Bir gün yine o kadar sıkıştı. Ben yarım saat uğraştım. Kan ter içinde kaldım. Çorabımı sıksaydınız, çorabımdan bir bardak su akacaktı. Hasta yakını hastası normale dönünce doktora; çok sağ olun elinize sağlık deyip bana da hiçbir şey demeden gitti (E,32y).

Hemşireler, hasta yakınlarının, yoğun bakımda hastalara verilen tedavi ve bakım hizmetlerinin çok da farkında olmadıklarını düşünmektedirler. Elbette bunun altında yatan neden yoğun bakım ünitelerinin kapalı birimler olması olabilir. Ancak yine de hemşirelerin ortak olarak "saygı" kavramı üzerinde durmasının önemli bir bulgu olduğu düşünülmektedir. 


\section{Ana tema 3. Hasta yakınları empati kurabiliyor mu?}

Hemşireler genel olarak hasta yakınlarının kendilerini anlamadıklarını ve empati kuramadıklarını belirttiler.

Bazıları anlıyor, bazıları anlamıyor. Devletin hasta hakları diye bir şey oluşturduğunu ama hekimin ve hemşirenin hakkı yok diye biliniyor ama böyle değil. Sonuçta nasıl ki hasta ve hasta yakınlarının hakları varsa bizim de haklarımız var. Ama medyada ve hastane protokollerinde hasta hakları üzerinde durulduğu için kendilerini öncelikli görüp bize saygısızca davranıyorlar (E,32y).

Bizim duygularımızı anladıklarını düşünmüyorum. Nasıl bir ortamda nasıl bir yoğunlukta çalıştı̆̆ımızın kesinlikle farkında değiller (K,зоy).

Kuramıyor. Hasta yakınları mesela bilgi almak, konuşmak istiyorlar ama bir doktora gösterdiği saygıyı size göstermiyor. Aslında içerde birebir biz hastasına bakıyoruz. Bizim verdiğimiz bakımla yaşıyor. Tedavi de önemli ama bakım çok daha önemli ki bizimkiler inme hastaları $(\mathrm{K}, 33 \mathrm{y})$.

Bazen çok gergin tipler oluyor. Hepsiyle çok iyi, süper değiliz. Bazıları çok bencil olabiliyor, her şeyin onların etrafında dönmesini istiyor. Anlatıyorsun ama anlamıyor (K,40y).

\section{Ana tema 4. Çalışmaya başladıktan sonraki duygu ve düşünceler}

Katılımcıların genel ifadelerinden nörolojik yoğun bakımda yatan hastaları ve bakım ihtiyaçlarını gördükten sonra duygularının olumlu yönde değiştiği anlaşılmaktadır.

Bizim nörolojik hastaların prognozu çok iyi olmadığı için psikolojik olarak etkilenmedim diyemem. Ama gene de hastalara faydalı olabilmek adına soğukkanlı olmaya çalıştım. Tabii neticede sadece inme gibi düşünmeyelim, prognozu çok kötü seyredenler de olabiliyor. İster istemez etkileniyorsunuz (K,49y).

Bana olumlu yaklaşan hasta yakınları olduğu zaman yaptığım işten mutluluk duyuyorum işe daha severek sarılıyorum. Diğer kliniklerde çalışan hemşirelere göre yoğun bakım işi yükü fazla. Bilmeden değerlendirilip bütün emeğimiz çöpe atılmamalı (K,47y).

Empati kurmayı daha çok öğreniyorsun. Çünkü yakının da olabilir diye düşünüyorsun. Duygu ve düşünce olarak daha anlayışlı olmayı kazandırdı diyebilirim (K,40y). 
Hemşireler, nörolojik yoğun bakımda bağımlılık düzeyi yüksek, prognozu kötü olan hastalara bakım verme sürecinden psikolojik olarak etkilenseler de bu duygularla başa çıktıkları anlaşılmaktadır.

\section{Ana tema 5. Beklentiler}

Hasta yakınlarının hemşirelerle daha iyi iletişim kurabilmesi için kurumdan beklentileri soruldu. Kurumdan beklentilerinin genel olarak hasta yakınlarının iş yükünü azaltmaya yönelik kurum koşullarının iyileştirilmesi, psikolojik destek sağlanması, çalışan sayısının arttırılması olduğu anlaşılmaktadır.

Yoğun bakımda son zamanlarda çok genç hastalarımız oluyor. Multiple Skleroz, nöromüskülerin hastaları genç olduğu için hasta yakınlarının psikolojik destek almaları gerektiğini düşünüyorum (K,47y).

Personel olmadığı için birçok şeyi halletmeye çalışıyoruz ama yöneticiler bazı şeyleri göremiyor. Daha iyi olanaklar olsa keşke (K,40y).

Mesela hasta yakınları nerede oturayım diye soruyor? Diyorsun ki asansörün orada iki tane tahta sandalye var onun üzerine oturun. Burada kalacaklarsa bir imkan hazırlansın. Bir de bence en önemli şey hasta yakınlarına bilgi verilmesi. Belki halkla ilişkiler olabilir. O hasta yakınlarını eğitebilir. Yeterli derecede bilgi sahibi olsalar hasta yakınları da irrite olmaz diye düşünüyorum. İster istemez ajiteleşiyorlar, yeteri kadar bilgilendirirseler belki bu kadar kötü olmazdı iletişimleri (K,33y).

Bizi biraz daha rahat şartlarda çalıştırabilirlerse bizde onlarla iletişim kurmaya zaman ayırabiliriz. Mesela ben işe bir başlayacağım, uzun bir süre içerden çıkamayacağım o yüzden de doğru düzgün bana gelseler bile kısa cevapla göndereceğim (K,зоy).

En büyük sorunlarımızdan bir tanesi personelimiz yok. Kan alıyoruz, ya da bir yere tahlil gidecek bunu hasta yakınlarıyla halletmeye çalışıyoruz. Bundan dolayı hasta yakınları bir o tarafa bir bu tarafa gidiyorlar, yoruluyorlar (E,32y).

Hasta yakınlarının bekleyebileceği düzgün bir yer olması çok önemli. Biz hasta yakınlarının hastanede kalmasını istiyoruz çünkü ne zaman ihtiyaç duyacağımız belli değil. Gitme dediğimiz anda o insanlara gösterebileceğimiz yer yok öyle olunca nereye gidiyor belli değil. Hasta yakınını aramak için işinizi gücünüzü bırakıp 5-10 dakika telefonunuzla ariyorsunuz (K,47y). 
Malzemeye daha çok ulaşılabilir olabilir. Çünkü zor ulaşıyoruz malzemeye (K,35y).

Hemşireler, hasta yakınlarıyla iletişimin kolaylaştırılması için kendileriyle ilgili koşulların iyileştirilmesinden çok hasta yakınlarının iş gücünü azaltan ve konforunu sağlayan beklentilerinin olduğu anlaşılmaktadır.

\section{Tartışma}

Hemşireler, hastanın bakım ve önerilen tedavisini sürdürürken aynı zamanda hastaailesiyle ilişkilerin yürütülmesinde de rol alırlar. Bu nedenle bu çalışmada hemşirelerin nöroloji yoğun bakımda yatan hastaların yakınlarıyla iletişim kurarken yaşadıkları ayrıntılı olarak incelenmek amaçlanmıştır. Hemşirelerin genel olarak hasta yakınlarının kendileriyle iletişim kurma şeklinden memnun olmadıkları, onların olumsuz davranışlarının günlük yaşamlarını ve iş motivasyonlarını etkilediği anlaşıldı. Hasta yakınlarının kendilerine davranışlarını "saygısızca” ve "empati yoksunu” olarak değerlendirdikleri görüldü. Ayrıca hemşireler hasta yakınlarıyla daha olumlu iletişim kurulabilmesi için kurumdan beklentileri oldukları anlaşıldı.

Bireylerin istedikleri mesleği seçmeleri iş tatminini arttırmaktadır. Bu çalışmaya katılan hemşirelerin çoğunluğunun mesleklerini kendileri seçtiklerini belirtmelerine rağmen sadece bir tanesinin yoğun bakım ünitesinde çalışmak istediği anlaşılmıştır. Gönüllü olarak yoğun bakımda çalışmayan hemşireler çalışma ortamlarında olumsuz algıya sahip olabilmekte ve yeterli destek alamadıklarını bildirmektedirler. Yine aynı şekilde mesleğini ve çalışma ortamını kendi seçen hemşirelerin iş memnuniyetlerinin ve iş doyumlarının arttığı bildirilmektedir ${ }^{18}$. Yapılan başka bir çalışmada da hemşirelerin mesleklerini kendi tercih etmemelerinin (ailenin istemiş olması, ekonomik kaygılar vb.) tükenmişlik yaşamalarına ve işi bırakmalarına yol açtığı bildirilmektedir ${ }^{19}$. Bu çalışmadaki hemşirelerin çoğu mesleklerini kendileri seçmiş olsalar da çalıştıkları bölümü seçmemeleri iş ortamı algılarını olumsuz etkilenmesine ve hasta yakınlarının davranışlarından memnun olmamalarına yol açtığı düşünülmektedir.

Hemşirelere hasta yakınlarıyla yaşadıkları iletişim sorunlarının günlük yaşamlarına yansıması ve çalışma koşullarının hasta yakınlarıyla iletişımlerini etkileyip etkilemediği soruldu. Katılımcıların genel olarak günlük yaşamda yaşadıkları olumsuzlukları hasta yakınlarına yansıtmadıkları ancak hasta yakınlarıyla yaşadıkları olumsuzlukların günlük yaşamlarını etkileyerek stres yaşamalarına yol açtığı anlaşıldı. Diğer yandan çalışma 
koşullarına bağlı nedenlerin de hasta yakınlarının olumsuz iletişimine yansıdığı görüldü. Yapılan çalışmalarda hemşirelerin profesyonel hayatındaki bir takım zorlukların günlük yaşamlarında strese yol açtığı bildirilmektedir. Bu zorluklar içinde meslekten memnun olma durumu, çevre koşulları ve insan ilişkilerinin karmaşıklığı yer almaktadır ${ }^{20}$. Aynı zamanda hemşirelerin profesyonel sorumluluklarını aşan fiziksel ve psikolojik zorluklarla mücadele etmeleri de günlük yaşamlarını etkiler²1. Hemşireler çoğu zaman uygun fiziksel koşullarda çalışamamaktadır. Yetersiz fiziksel koşulların getirdiği zorluklar hasta yakınlarına yansımakta ve onlar da bu sorunları en çok gördükleri sağlık profesyoneli olan hemşirelere aktarmaktadırlar. Literatüre paralel olarak hemşirelerin yaşadıkları fiziksel ve psikolojik zorlukların hasta yakınlarına yansımasıyla iletişim kurma güçlüklerinin yaşanmasına yol açtığı düşünülmektedir.

Empati, diğer insanların yararına olacak şekilde davranma olarak tanımlanır ve temel hemşirelik etik prensiplerinden biridir ${ }^{22,23}$. Bu çalışmada da hemşirelerin hasta yakınlarının yaşadıkları anksiyeteyi anladıkları ve empati geliştirdikleri anlaşılmaktadır. Ancak hasta yakınlarının kendilerine bekledikleri saygıyı göstermedikleri ve empati kuramadıklarını belirtmişlerdir. Kişi, stres yaşadığında temel hedefi kendi endişesinin ve stresinin azaltılması olabilir ve o anda empatik davranış geliştirmeyebilir ${ }^{24}$. $\mathrm{Bu}$ durumda empati kuran kişi sıkıntısıyla orantılı olarak kendi duygularını kontrol edemeyebilir. Toplum yanlısı bir davranış olan empati, kişi kendi duygularını düzenleme yeteneğine sahip olduğunda gerçekleşir ${ }^{25}$. Yoğun bakım üniteleri kritik hastaların yattığı yerler olması nedeniyle hasta yakınlarının daha fazla stres ve anksiyete yaşamaları kaçınılmazdır. Yaşadıkları yüksek strese bağlı olarak hemşirelerle kurdukları iletişimde empati kuramadıkları düşünülmektedir.

Hemşirelerle yapılan çalışmalarda çalışma ortamıyla ilgili yetersizlikler, yoğun iş yükü gibi pek çok nedenin tükenmeye ve iş bırakmaya yol açtığg bildirilmektedir ${ }^{26,27}$. Ancak bu çalışmadaki hemşireler benzer koşullardan mağdur olsalar da yoğun bakımda çalışmaya başladıktan sonra duygu ve düşüncelerinde olumlu değişiklikler olduğunu bildirmiştir. Yoğun bakımlar hastaların bağımlılık oranı ve bakım ihtiyaçlarının yüksek olduğu birimlerdir. Dolayısıyla hemşireliğin temelinde yer alan "bakım” kavramının en fazla uygulandığı yerdir²8. Bu çalışmaya katılan hemşirelerin de hastaların bakım ihtiyacını gördükten sonra duygularında olumlu değişiklik olmasını mesleğin getirdiği güdülere bağlanabileceği düşünülmektedir. Ayrıca yapılan çalışmalarda hemşirelerin 
mesleklerinin başlangıcında mesleği bırakıp bırakmama ikilemini yaşayarak kendilerini sorguladıkları ve sonrasında işin zorluklarına uyum sağladıkları belirtilmektedir. Aynı zamanda hemşireler tecrübe kazanarak kendilerini güçlendirmekte ve yetkinliklerini geliştirmektedirler ${ }^{29,30}$. Bu çalışmaya katılan hemşirelerin de ortalama çalışma sürelerinin uzun olması mesleğe bakışlarını zamanla daha olumlu hale getirmiş olabilir. Hemşirelere hasta yakınlarının kendileriyle daha iyi iletişim kurmak için beklentileri sorulduğunda hastane fiziki koşullarının iyileştirilmesini, personel eksikliğinin giderilmesini ve psikolojik destek sağlanmasını beklediklerini belirtmişlerdir. Hemşireler, ailenin yoğun bakım ortamını deneyimlemesinde, başa çıkmasında anahtar rol oynar ${ }^{11}$. Ancak iletişim sorunları, sağlık çalışanları ve aileler arasında önemli bir problemdir. $\mathrm{Bu}$ problem kişilerin bakım ve tedavi tercihlerinin planlanmasını ve hedeflerin oluşturulmasını engelleyebilir ${ }^{32}$. Bu sorunu kuruma bağlı olarak bilgilendirme zayıflıkları, bakım koordinasyonundaki güçlükler gibi olumsuzluklar da etkiler33. Yapılan çalışmalarda hasta yakınları hemşire ve doktorların verdikleri bilginin nasıl verildiğine veya sağllk profesyonellerinden bilgi edinme güçlüklerine yönelik kötü deneyimler bildirmiştir ${ }^{11,34}$. Yine eksik elemanla çalışma ve iş yoğunluğunun iletişimi etkilediği bildirilmiştir35. Hemşirelik hizmetlerinin kaliteli ve doğru bir şekilde sunulabilmesi için hastane yönetimlerinin planlama ve organizasyon yapması önemlidir ${ }^{36}$. Yapılan araştırmalar ve bu araştırmaya katılan hemşirelerin de yaptığı tespitler doğrultusunda hasta yakınlarının olumsuz iletişimi hastane ve yoğun bakım ortamı, personel eksikliği gibi faktörlerden etkilenebilmektedir.

\section{Kisıtlılıklar}

Çalışmanın tek bir nöroloji yoğun bakım ünitesinde gerçekleştirilmesi sonuçların genelleştirilmesini zorlaştırmaktadır. Diğer yandan çalışmanın gerçekleştirildiği üniversite hastanesinin İstanbul'un en büyük hastanelerinden biri olmasının önemli olduğu düşünülmektedir. Bir diğer kısıtlılık da çalışma verilerinin toplandığı yerin hastane ortamı olmasıdır. Nöbet öncesi ya da sonrası gerçekleştirilen görüşmeler katılımcılar üzerinde zaman baskısı yaratmış olabilir.

\section{Sonuç}

Nöroloji yoğun bakım hemşirelerinin, hasta yakınlarının iletişim kurma şeklinden hoşnut olmadıkları, olumsuz davranışlarının iş motivasyonlarını azalttığı ve hasta 
yakınlarıyla iletişimlerinin düzeltilmesi için beklentilerinin olduğu anlaşılmaktadır. Bu çalışmayla toplumun sağlık çalışanlarının görev ve sorumlulukları açısından bilinçlendirilmesi ve hemşirelerin gözüyle hasta yakınlarının iletişiminin gözlenmesi açısından katkı sağlayacağı düşünülmektedir.

\section{KAYNAKLAR}

1. World Health Organization. Neurological disorders: public health challenges. https://www.who.int/mental health/neurology/neurodiso/en/. Erişim Tarihi 20 Kasim 2020

2. Bolton CF. Neuromuscular manifestations of critical illness. Muscle \& Nerve: Official Journal of the American Association of Electrodiagnostic Medicine. 2005;32(2):140-163.

3. Topcuoğlu AM, Kocaman Sağduyu A, Öztürk Ş, Nazliel B, Şirin H. Türkiye’de nörolojik yoğun bakım. Türk Nöroloji Dergisi. 2011;17(1):7-16.

4. Rubinos C, Ruland S. Neurologic complications in the intensive care unit. Current neurology and neuroscience reports. 2016;16(6):57-74.

5. Adam S, Osborne S, Welch J. Critical Care Nursing: Science and Practice. Oxford University Press; 2017.

6. Arslanian-Engoren C, Scott LD. Clinical decision regret among critical care nurses: a qualitative analysis. Heart \& Lung. 2014;43(5):416-419.

7. Leung D, Blastorah M, Nusdorfer L, et al. Nursing patients with chronic critical illness and their families: a qualitative study. Nurs Crit Care. 2017;22(4):229237. doi:10.1111/nicc.12154.

8. Leung D, Angus JE, Sinuff T, Bavly S, Rose L. Transitions to end-of-life care for patients with chronic critical illness: a meta-synthesis. American Journal of Hospice and Palliative Medicine. 2017;34(8):729-736.

9. Nelson JE, Kinjo K, Meier DE, Ahmad K, Morrison RS. When critical illness becomes chronic: informational needs of patients and families. $J$ Crit Care. 2005;20(1):79-89. 
10. Baysal EG. Sağlık Çalışanlarının Hastalarla Olan İletişim Problemlerine Yönelik Bir Alan Çalışması: Diyarbakır Gazi Yaşargil Eğitim ve Araştırma Hastanesi Örneği. [yüksek lisans tezi]. İstanbul, Türkiye: Beykent Üniversitesi Sosyal Bilimler Enstitüsü;2014.

11. Baykal D, Tütüncü SK. Yoğun bakımdaki sağlık çalışanlarının hasta yakınlarıyla olan iletişiminin araştırılması. İstanbul Gelişim Üniversitesi Sağlık Bilimleri Dergisi. 2017;(1):33-47.

12. Wysham NG, Mularski RA, Schmidt DM, et al. Long-term persistence of quality improvements for an intensive care unit communication initiative using the VALUE strategy. Journal of critical care. 2014;29(3):450-454.

13. Wysham NG, Hua M, Hough CL, et al. Improving intensive care unit-based palliative care delivery: a multi-center, multidisciplinary survey of critical care clinician attitudes and beliefs. Critical care medicine. 2017;45(4):e372.

14. Courvoisier DS, Agoritsas T, Perneger TV, Schmidt RE, Cullati S. Regrets associated with providing healthcare: qualitative study of experiences of hospital-based physicians and nurses. PloS one. 2011;6(8):e23138.

15. Radtke K. Improving patient satisfaction with nursing communication using bedside shift report. Clin Nurse Spec. 2013;27:19-25. doi:10.1097/NUR.obo13e3182777011

16. Boykins AD. Core communication competencies in patient-centered care. $A B N F$ J. 2014;25:40-45.

17. Yoo HJ, Lim OB, Shim JL. Critical care nurses' communication experiences with patients and families in an intensive care unit: a qualitative study. Plos one. 2020;15(7):e0235694.

18. Kahraman G, Engin E, Dülgerler Ş, Öztürk E. The job satisfaction of critical care unit nurses and affecting factors. DEUHYO ED. 2011;4:12-8.

19. Kocaman, E. Hemşirelerde Tükenmişlik ile Rol Çatışması ve Rol Belirsizliği Arasındaki İlişki: Çorlu Devlet Hastanesi Örneği. [yüksek lisans tezi]. Tekirdağ, Türkiye: Namık Kemal Üniversitesi Sosyal Bilimler Enstitüsü Sağlık Yönetimi Anabilim Dalı;2015. 
20. Franco GP, de Barros AL, Nogueira-Martins LA, Zeitoun SS. Burnout in nursing residents. Revista da Escola de Enfermagem da USP. 2011;45(1):12-18.

21. Da Silva APF, Carneiro LV, Ramalho JPG. Incidence of burnout syndrome in nursing professionals in intensive therapy unit. Revista de Pesquisa, Cuidado é Fundamental Online. 2020;12:915-920.

22. Penner LA, Dovidio JF, Piliavin JA. Prosocial behavior: Multilevel perspectives. Annual Review of Psychology. 2005;56:365-392.

23. Austin W, Goble E, Leier B. Compassion fatigue: The experience of nurses. Ethics and Social Welfare. 2009;3(2):195-214.

24. Rushton CH, Kaszniak AW, Halifax JS. A framework for understanding moral distress among palliative care clinicians. Journal of Palliative Medicine. 2013;16(9):1074-1079.

25. Decety J, Yoder KJ. Empathy and motivation for justice: Cognitive empathy and concern, but not emotional empathy, predict sensitivity to injustice for others. Social Neuroscience. 2015;11(1):1-14.

26. Labrague LJ, McEnroe-Petitte DM, Gloe D, Tsaras K, Arteche DL, Maldia F. Organizational politics, nurses' stress, burnout levels, turnover intention and job satisfaction. International nursing review. 2017;64(1):109-116.

27. Al Sabei SD, Labrague LJ, Miner Ross A, et al. Nursing work environment, turnover intention, job burnout, and quality of care: the moderating role of job satisfaction. Journal of Nursing Scholarship. 2020;52(1):95-104.

28. Kitson AL. The fundamentals of care framework as a point-of-care nursing theory. Nursing Research. 2018;67(2):99-107.

29. Duchscher JB. A process of becoming: the stages of new nursing graduate professional role transition. J. Contin. Educ. Nurs. 2008;39(10):441-450.

30. Liang HF, Lin CC, Wu KM. Breaking through the dilemma of whether to continue nursing: Newly graduated nurses' experiences of work challenges. Nurse Education Today. 2018;67:72-76. 
31. Hetland B, Hickman R, McAndrew N, Daly B. Factors influencing active family engagement in care among critical care nurses. AACN advanced critical care. 2017;28(2):160-170.

32. Nelson JE, Hope AA. Integration of palliative care in chronic critical illness management. Respiratory care. 2012;57(6):1004-1013.

33. Roulin M, Spirig R. Developing a care program to better know the chronically critically ill. Intensive Crit. Care Nurs. 2006;22:355-361. doi:10.1016/j.iccn.2006.02.004.

34. Wong P, Liamputtong P, Koch S, Rawson H. Families' experiences of their interactions with staff in an Australian intensive care unit (ICU): a qualitative study. Intensive and Critical Care Nursing. 2015;31(1):51-63.

35. Besey Ö, Dağcı S. Yoğun bakım ünitelerinde çalışan hemşirelerin karşılaştıkları sorunlar. Yoğun Bakım Hemşireliği Dergisi. 2020;24(3):170-183.

36. Yeşiltaş A, Gül İ. Hemşirelerin çalışmak için tercih ettikleri birimler ve tercih nedenleri. MAKÜ Sag. Bil. Enst. Derg. 2016;4(2):74-87. 